\title{
NEUROLEPT ANAESTHESIA: A COMPARISON WITH A CONVENTIONAL TECHNIQUE FOR MAJOR SURGERY*
}

\author{
S. A. McDowELL, M.B., F.F.A.R.C.S. AND J. W. DuNDEE, M.D., PH.D., F.F.A.R.C.S.
}

IN THE PAST DECADE, the term "neuroleptic" has been increasingly used to describe the effects of certain drugs on the central nervous system. It is usually used to signify the production of tranquillity and mental detachment, without a marked soporific effect. If a narcotic analgesic is used in combination with a neuroleptic drug, then a state of neurolept-analgesia is produced and if, in this state, a hypnotic is added to produce sleep, the result is neurolept anaesthesia (NLA).

Since the introduction of this form of anaesthesia by De Castro and Mundeleer ${ }^{1}$ a great variety of techniques of NLA have been described and many claims made for its advantages over more conventional forms of anaesthesia. ${ }^{2-6}$ Among these are:

(a) stability of the cardiovascular system, making it particularly suited for the poor-risk patient.

(b) profound analgesia, which extends into the postoperative period and results in comfort for the patient and ease of management.

(c) little postoperative nausea and vomiting.

(d) rapid recovery of consciousness with good tolerance of endotracheal tubes and patient cooperation.

In spite of these advantages, neuroleptanaesthesia has not found acceptance with all workers ${ }^{7}$ and recently, the usefulness of the drugs used in NLA has been questioned by workers from this department. ${ }^{8,9}$

The neuroleptic drug commonly used in this form of anaesthesia is droperidol and it is usually given in conjunction with the analgesic fentanyl. A 50:1 mixture of these two drugs is available commercially as Thalamonal ${ }^{\mathbb{B}}$ or Innovar ${ }^{\circledR}$. The object of the present study was to look critically at NLA as used for major surgery, bearing in mind the claims which have been made for it. Previous work in this department has demonstrated that the thiopentone-relaxant-nitrous oxide-oxygen technique is greatly enhanced by the addition of $2 \mathrm{mg}$ of levorphanol (Dromoran $\left.{ }^{\circledR}\right) .{ }^{10}$ This technique was therefore taken as a standard with which to compare four other techniques involving the use of fentanyl and droperidol.

The study was carried out on patients undergoing cardiac, thoracic or major abdominal surgery, since these were most readily available to the authors. The allocation of techniques will be described in detail later.

\section{Premedication}

A standard premedication of $50 \mathrm{mg}$ meperidine and $0.6 \mathrm{mg}$ atropine was given to all patients in the study. This helped to cut down variables and allowed a technique to be changed at short notice if this was necessary.

'Department of Anaesthetics, The Queen's University of Belfast, Northern Ireland. 


\section{Techniques}

The five techniques are described below. The standard one is outlined in detail, the others being identical to it with the exception of the drugs used. All patients had continuous electrocardiographic monitoring throughout the course of anaesthesia and all had an intravenous infusion of lactate Ringer's solution, which was started immediately after induction

Technique L. Induction was with thiopentone $5 \mathrm{mg} / \mathrm{kg}$. Following $2.0 \mathrm{mg}$ levorphanol and $30 \mathrm{mg}$ tubocurarine, the patient was ventilated with nitrous oxide $5 \mathrm{l} / \mathrm{min}$ and oxygen $3 \mathrm{l} / \mathrm{min}$ for 3 minutes before intubation. Maintenance of anaesthesia was with nitrous oxide/oxygen (in the ratio of 5:3) using mechanically controlled ventilation by a Cape Waine ventilator. During maintenance, supplements of levorphanol $1 \mathrm{mg}$ were added for small movements of the patient's hands, feet or face and also for sweating, tachycardia and raised blood pressure. If these occurred near the end of operation, 0.5 per cent halothane was added for a few minutes. Supplements of tubocurarine $5 \mathrm{mg}$ were added for unsatisfactory surgical conditions, movement of the diaphragm, and gross limb movements.

Neostigmine $2.5 \mathrm{mg}$ (with atropine $1.2 \mathrm{mg}$ ) was used to reverse residual muscle paralysis at the end of surgery and the nitrous oxide was turned off at the same time as neostigmine was given. If muscle power had not returned within five minutes, a further $1.25 \mathrm{mg}$ neostigmine was injected.

Technique $\mathbf{F}$. This was identical to $\mathrm{L}$ except for the use of fentanyl $0.2 \mathrm{mg}$ in place of levorphanol at induction. Supplements of fentanyl $0.1 \mathrm{mg}$ were used in place of levorphanol $1.0 \mathrm{mg}$.

Technique FD. This was identical to $\mathrm{F}$ except for the addition of $5.0 \mathrm{mg}$ droperidol along with fentanyl at the induction.

Technique NLF. Induction was with fentanyl/droperidol mixture containing 0.05 $\mathrm{mg}$ fentanyl and $2.5 \mathrm{mg}$ droperidol per $\mathrm{ml}$ (referred to hereafter by its trade name Innovar). The initial dose of $1 \mathrm{ml} / 12 \mathrm{~kg}$ was given over $2-3$ minutes. If the patient was not asleep within 4 minutes, 1 -ml increments were added at minute intervals until consciousness was lost. Thirty $\mathrm{mg}$ of tubocurarine were given and the patient ventilated with nitrous oxide $5 \mathrm{~L} / \mathrm{min}$ and oxygen $3 \mathrm{~L} / \mathrm{min}$ for 3 minutes before intubation was attempted. Fentanyl $0.1 \mathrm{mg}$ was used as an analgesic supplement during maintenance of anaesthesia.

Technique NL. This was identical to NLF except that supplements of analgesia were with $1 \mathrm{ml}$ of the fentanyl/droperidol mixture.

All anaesthetics were given personally by one or other of the authors and often by both working together.

\section{Observations During Anaesthesia}

From the point of view of comparing the five techniques under investigation, the course of anaesthesia was divided into four parts: induction (including intubation), maintenance, recovery, and the postoperative period. The observations which formed the basis for comparison of cases are detailed below. 


\section{Induction}

Blood pressure and pulse rate were recorded every 2 minutes.

Respiratory difficulties (prior to giving tubocurarine) were graded as:

- marked when there was difficulty in inflating the patient (other than anatomical difficulties)

- slight when respiratory depression could be overcome by asking the patient to breathe.

Other induction complications were noted as they occurred.

Intubation was graded as easy or difficult.

Response to intubation was noted, including limb movements, cough and electrocardiographic abnormalities.

Ease of settling. The 15 minutes immediately following intubation were considered as the "settling period" and included positioning of the patient and the start of surgery. Three grades of settling were recognised:

- marked difficulty if 3 or more supplements (relaxant or analgesic) were required during this period.

- slight difficulty if 1 or 2 supplements were required.

- no difficulty if no supplements were used.

\section{Maintenance}

Blood pressure was estimated every 5 minutes during the course of anaesthesia. The overall pattern of blood pressure during maintenance was recorded as:

- very unstable: a change of pressure (rise or fall) exceeding $30 \mathrm{~mm} \mathrm{Hg}$ on more than 3 occasions

- slightly unstable: a change of pressure (rise or fall) exceeding $20 \mathrm{~mm} \mathrm{Hg}$ but less than $30 \mathrm{~mm} \mathrm{Hg}$ on 3 occasions, or a single blood pressure swing greater than $30 \mathrm{~mm} \mathrm{Hg}$.

- stable: Blood pressure changes not exceeding $20 \mathrm{~mm} \mathrm{Hg}$.

The overall level of blood pressure throughout the course of anaesthesia was graded as normal, high or low.

Pulse rate was also recorded at 5-minute intervals and using criteria similar to those for blood pressure, the pattern of the pulse rate was recorded as stable, slightly unstable or very unstable and as normal, fast or slow.

Others. The presence of such complications as sweating, small facial or hand movements, pallor, swallowing or hiccough were noted during maintenance by carefully arranging the dirapes in such a way that the patient's head, neck and one arm could be easily observed by the anaesthetist. They were recorded as:

brief: ended by a single supplement (usually analgesic)

prolonged: persisted in spite of further supplementation

recurrent: ended by supplementation but recurred later.

Overall smoothness. This was recorded at the end of each anaesthetic and was a clinical impression of how satisfactory maintenance of anaesthesia had been. Three grades were recognised - satisfactory, slight difficulty and marked difficulty. 


\section{Recovery}

This covered the period from the withdrawal of nitrous oxide (and coincidental injection of neostigmine) until the patient left the operation room. The observations made during the period included

- the time (minutes) from the injection of neostigmine until the onset of spontaneous respiration.

- the time from withdrawal of nitrous oxide until the patient responded to command

- the response to extubation (performed when spontaneous respiration became established) graded as violent cough, slight cough or nil.

If a delay in the return of respiration or consciousness occurred, notes were made on the probable causes (e.g. continuing paralysis, respiratory depression) and on the appropriate treatment instigated.

- other complications such as sweating, vomiting, restlessness.

\section{Postoperative Period}

All patients were visited 15 minutes, 30 minutes and 60 minutes after their return to the recovery room. At each visit, the following observations were made:

- level of consciousness (classed as awake, easily roused, hard to rouse, unrousable)

- degree of pain (classed as nil, slight, severe, very severe) based on patient's opinion

- blood pressure, pulse rate and respiratory rate

- the presence of complications such as sweating, restlessness, pallor, nausea and/ or vomiting.

Between 60 and 90 minutes postoperatively an arterial blood sample was taken for $\mathrm{PCO}_{2}$ and acid/base studies.

The analgesic drug used in the postoperative period was methadone $(5-10 \mathrm{mg}$ doses), given intramuscularly when it was considered that pain was sufficiently severe. A note was made of the time from the end of anaesthesia until the first dose of analgesic was given and the total dose of methadone used in the 24 hours following surgery was recorded.

\section{Design OF STUDY}

The study was designed to use the sequential method of analysis, as described by Armitage, ${ }^{11}$ using the "multiple-preference" modifications employed by Dundee and colleagues. ${ }^{10,12,13}$ In this, a pair of patients as identical as possible with respect to age, sex, physical status and nature of the surgical operation, is anaesthetized with two of the techniques being studied. The records of the two cases are compared in detail and "preferences" for the more satisfactory administration allocated on a clinical basis. Minor differences are ignored and if the course of the two anaesthetics is similar then "no preference" is recorded.

The five points of comparison and the basis for the comparisons, were:

Induction: Extent and duration of blood pressure and pulse rate changes and the ease of intubation, which was first attempted 3 minutes after administration of tubocurarine. 
Ease of settling: Supplementary doses of either analgesic or relaxant required because of movement of patient or difficulty in controlling ventilation.

Smoothness of maintenance: Stability of blood pressure and heart rate and the occurrence of sweating, vasoconstriction or pallor, hiccough or persistent movement of patient.

Emergence: Time to return of consciousness and return of adequate spontaneous ventilation. Need for repeated doses of neostigmine or analgesic antagonist. Presence of complications as patient was leaving operating room.

Postoperative course: Cardiovascular and respiratory state for first hour in recovery ward. Acid-base state, level of consciousness, occurrence of nausea and vomiting, sweating or pallor. Degree of pain, time to first postoperative analgesic and dose required during first 24 hours after operation.

From these an overall preference (or no preference) was expressed for one or other technique in the pair of cases studied. Great care was taken to ensure that the differences between the two anaesthetics were of real clinical importance.

\section{Allocation of Cases}

The 5 techniques were studied concurrently and random lists of the order in which these would be used were drawn up in advance. Relevant data about the first patient in a set (age, operation, etc.) were recorded and when another similar case presented the next technique in the series was used. This was continued until all five similar patients were anaesthetised, each with a different technique. Because of the nature of the cases available to the authors there was a preponderance of cardio-thoracic surgery.

There were 10 possible comparisons between techniques but only four were made. The thiopentone-nitrous oxide-levorphanol sequence (Technique L) was considered to be the standard one and this was compared with each of the other four.

For each comparison, a restricted sequential graph was drawn having the characteristics

$$
\theta=0.85 ; \quad \alpha=0.05 ; \quad \beta=0.05
$$

In this, the horizontal line shows the number of pairs of patients in which a definite preference was shown for one or other technique (Figure 1). Where a preference is made for one technique, a line is drawn up and to the right, while a preference for the other is indicated by a line down and to the right. This sequence of comparisons between cases is continued until one or other boundary of the graph is crossed. Crossing the upper or lower boundary indicates a significant difference $(p<0.05)$ for the appropriate technique, while crossing the wedge-shaped middle boundary shows that the difference was not significant. Thus the vertical axis indicates the differences in the number of preferences with the two techniques compared (the "excess" preference).

Technique $\mathrm{F}$ proved very inferior compared with the standard one ( $L$ ) and the sequential graph showed the differences to be significant after 12 pairs of cases. This part of the study was then terminated. The other 4 techniques were continued until the overall comparison of $\mathrm{L}$ with NLF crossed the boundary line after 25 pairs 


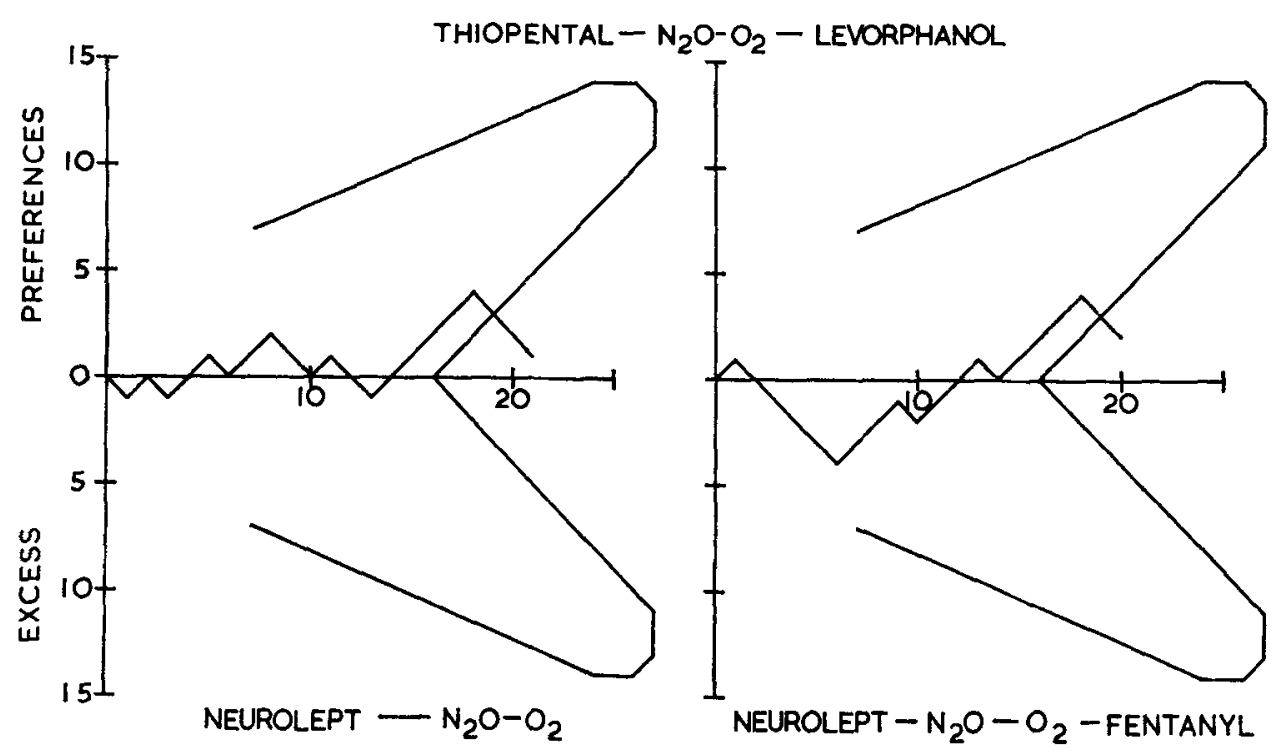

FIGURE 1. Sequential graph demonstrating over-all difference between control technique (thiopentone-nitrous oxide-oxygen-levorphanol), neurolept-nitrous oxide-oxygen, and neuroleptnitrous oxide-oxygen-fentanyl. Horizontal line indicates total number of preferences recorded out of 25 pairs of cases in each study. The graph shows that there was no overall significant difference between the techniques compared.

of cases (Figure 1). Thus techniques $\mathbf{L}, \mathrm{FD}, \mathrm{NL}$, and NLF were each used on 25 identical cases. In presenting these findings a comparison of these four groups will be stressed (and also a similar comparison between $\mathrm{L}$ and $\mathrm{F}$ in 12 pairs of cases) rather than a detailed presentation of the findings of the various sequential graphs.

\section{Results}

Fentanyl proved so inferior to levorphanol as a supplement to thiopental-nitrous oxide-oxygen-relaxant that the relevant findings of this comparison will be shown first (Table I). Both the unsatisfactory maintenance and the short time until the administration of the first analgesic could be explained by the brevity of action of fentanyl and the use of this drug alone as a supplement will not be discussed further.

The nature of the operations and the physical status of the patients in each of the four main treatment groups is shown in Table II, while Table III shows mean doses of the drugs used in each technique.

Table IV analyses the induction of anaesthesia in detail. Induction hypotension was most marked with technique FD, the mean systolic pressure dropping from a control value of 130 to 77 immediately before intubation. The blood pressure falls in the other three techniques were very similar. All groups showed a rise in blood pressure after intubation, this being greatest when levorphanol was used. Intubation at the first attempt was accomplished more often when Innovar was used for induction rather than thiopentone, although the difference was very slight.

Respiratory difficulties did not occur in any patient induced with thiopentone and this is in marked contrast with the high incidence in the neuroleptic techniques. 
The mean time until surgery could have started (irrespective of the position of the patient) was much longer with Innovar induction than with thiopentone.

Pertinent data relating to the maintenance of anaesthesia is shown in Table $\mathrm{V}$. The number of patients whose blood pressure was within normal limits was similar in all four groups. However, the overall stability of the cardiovascular system was greatest in the control group (technique L). In this, blood pressure was classed as

TABLE I

Relevant Findings in the Comparison of Techniques I. AND F

\begin{tabular}{lcr}
\hline & \multicolumn{2}{c}{ Technique } \\
& L & F \\
\cline { 2 - 3 } & 12 & 12 \\
Number of patients & 2 & 5 \\
Induction & & \\
$\quad$ Difficulty settling & 4 & 9 \\
Maintenance of anaesthesia & 1 & 6 \\
Unstable BP & 2 & 5 \\
Unstable pulse rate & 2 & 8 \\
Sweating & & \\
Overall, very unsatisfactory & 2 & 6 \\
First analgesic required within 1 hour & 7 & 0 \\
First analgesic required after 4 hours & & \\
\hline L $=$ Thiopentone-nitrous oxide-oxygen-levorphanol & \\
F = Thiopentone-nitrous oxide-oxygen-fentanyl &
\end{tabular}

TABLE II

Details of Operation and Physical STATUS OF THE 25 PaTiENTS IN EACH Treatuent Grolp

\begin{tabular}{cr}
\hline Nature of operation \\
Mitral valvotomy \\
Upper abdoninal \\
Ling resection \\
Other thoracotomy \\
Physical status of patients \\
Asa grade 1 \\
2 \\
3 & 6 \\
\hline
\end{tabular}

TABLE III

Mean Dosts (MG) of Drugs Used in Each Thchique

\begin{tabular}{|c|c|c|c|c|}
\hline & \multicolumn{4}{|c|}{ Technique } \\
\hline & L. & Fil & NLF & NLA \\
\hline 'lubocurarine (mg) & 35.2 & $3 \overline{0.4}$ & 35.8 & 35.2 \\
\hline Levorphanol (mg) & 3.2 & - & - & - \\
\hline Fentanyl (nin) & $-\infty$ & 0.04 & 0.09 & 0.10 \\
\hline Droperidol (mg) & $\cdots$ & 5 & 41 & 48 \\
\hline \multicolumn{5}{|c|}{$\begin{array}{l}\text { is oxide-oxygen-levorphanol } \\
\text { us oxide-oxyyen-fentanyl with one dose of }\end{array}$} \\
\hline \multicolumn{5}{|c|}{$\begin{array}{l}\text { NLF = Innovar induction-nitrous oxide-oxygen-fentanyl main- } \\
\text { tenance }\end{array}$} \\
\hline \multicolumn{2}{|c|}{$\begin{array}{l}\text { NLA = Innovar induction-nitrous } \\
\text { tenance }\end{array}$} & oxide-o & en-Inno & main- \\
\hline
\end{tabular}


TABLE IV

Observations on Induction of Anaesthesia with the Four Main Techniques

\begin{tabular}{|c|c|c|c|c|}
\hline & \multicolumn{4}{|c|}{ Technique } \\
\hline & I & FD & NLF $F$ & NLA \\
\hline Control mean systolic BP $(\mathrm{mm} \mathrm{Hg})$ & $124 \pm 6$ & $130 \pm 5$ & $135 \pm 6$ & $137 \pm 6$ \\
\hline $\begin{array}{l}\text { Incidence of BP tall at ter induction: } \\
20-40 \mathrm{~mm} \mathrm{Hg}\end{array}$ & 8 & 7 & 7 & 9 \\
\hline $40+\mathrm{mm} \mathrm{Hg}$ & 15 & 15 & 11 & 12 \\
\hline Mean systolic BP (mm Hg): & & & & \\
\hline prior to intubation & $92 \pm 6$ & $77 \pm 5$ & $99 \pm 6$ & $97 \pm 8$ \\
\hline immediately after intubation & $118 \pm 4$ & $95 \pm 13$ & $107 \pm 7$ & $113 \pm 9$ \\
\hline Heart rate increases in excess of $20 / \mathrm{min}$ & 4 & 1 & 0 & 1 \\
\hline $\begin{array}{l}\text { Respiratory difficulties: } \\
\text { slight }\end{array}$ & & & & \\
\hline $\begin{array}{l}\text { slight } \\
\text { marked }\end{array}$ & $\begin{array}{l}0 \\
0\end{array}$ & $\begin{array}{l}0 \\
0\end{array}$ & $\begin{array}{r}16 \\
8\end{array}$ & $\begin{array}{r}17 \\
6\end{array}$ \\
\hline Easy intubation at first attempt & 21 & 23 & 24 & 24 \\
\hline Response to intubation & 11 & 8 & 7 & 6 \\
\hline Ease of settling & & & & \\
\hline slight difficulty & 6 & 5 & 4 & 6 \\
\hline marked difficulty & 0 & 3 & $\hat{1}$ & 1 \\
\hline $\begin{array}{l}\text { Mean time until patient considered ready } \\
\text { for surgery (min) }\end{array}$ & 10 & 10 & 17 & 16 \\
\hline
\end{tabular}

$\mathrm{L}=$ Thiopentone-nitrous oxide-oxygen-levorphanol.

$\mathrm{FD}=$ Thiopentone-nitrous oxide-oxygen-fentanyl with one dose of droperidol NLF $=$ Innovar induction-nitrous oxide-oxygen-fentanyl maintenance $\mathrm{NLA}=$ Innovar induction-nitrous oxide-oxygen-Innovar maintenance

TABLE V

Observations During Maintenance of Anaesthesia with the Four Main Techniques

\begin{tabular}{lrrrr}
\hline \multicolumn{1}{c}{ Maintenance } & L & FD & NLF & NLA \\
\hline Overall pattern of BP: & 5 & 2 & 2 & 4 \\
raised & 13 & 15 & 15 & 12 \\
within normal limits & 7 & 8 & 8 & 9 \\
low & 6 & 10 & 13 & 13 \\
slightly unstable & 3 & 3 & 0 & 3 \\
very unstable & 5 & 6 & 10 & 8 \\
Overall pattern of heart rate: & 17 & 16 & 12 & 13 \\
raised & 3 & 3 & 3 & 4 \\
within normal limits & 1 & 6 & 6 & 7 \\
slow & 0 & 1 & 2 & 1 \\
slightly unstable & 5 & 2 & 0 & 0 \\
very unstable & 15 & 11 & 9 & 9 \\
Prolonged or recurrent sweating & & & & \\
Prolonged or recurrent movement & 10 & 5 & 5 & 8 \\
Overall smoothness; & 6 & 5 & 4 & 2 \\
$\quad$ slightly unsatisfactory & & & & \\
very unsatisfactory & & & & \\
\hline
\end{tabular}

stable in 16 patients ( 64 per cent), compared with 12 patients ( 48 per cent) using techniques FD and NLF and 9 patients ( 36 per cent) using technique NLA. Few patients in any of the groups had very unstable blood pressure. Heart rate was also more stable in the control group than in any of the other three.

Excluding the cardiovascular effects, the overall smoothness of maintenance of anaesthesia was slightly more satisfactory when neuroleptic techniques were used. Completely satisfactory conditions occurred in 64 per cent of patients anaesthetised with technique NLF and in 40 per cent of those having NLA, compared with 36 per cent when the standard technique was used. The higher incidence of unsatisfactory 
Return of consciousness delayed more than 4 minutes Return of respiration delayed more than 4 minutes Cough on extubation

Any complication before leaving operating room

\begin{tabular}{rrrr}
\multicolumn{4}{c}{ Techniques } \\
L & FD & NLF & NLA \\
\hline 5 & 3 & 2 & 0 \\
6 & 3 & 4 & 3 \\
16 & 13 & 14 & 12 \\
1 & 6 & 5 & 2
\end{tabular}

Postoperative analgesia

Number requiring analgesia within 1 hour of surgery

Number not requiring analgesia during first 4 hours after surgery 16

Mean time to first dose (hrs)

Mean dose of methadone ( $\mathrm{ng}$ ) required in first 24 hours

\begin{tabular}{rrrr}
2 & 10 & 2 & 4 \\
16 & 7 & 11 & 9 \\
9 & 3 & 6 & 5 \\
19 & 24 & 21 & 20 \\
\hline
\end{tabular}

maintenance with technique $\mathrm{L}$ was due, in most cases, to the more frequent occurrence of sweating or movement (limbs, diaphragm, or face) by the patient. The incidence of very unsatisfactory maintenance of anaesthesia was similar in all four groups.

Table VI shows that there was little difference between the series with regard to recovery from anaesthesia. Return of respiration and/or consciousness was more often delayed with the levorphanol technique, but this may have been accounted for by the fact that halothane was more often used in this group, rather than repeating the long acting analgesic. The toleration of the endotracheal tube, as judged by the response to extubation, was little different in the control and neuroleptic techniques. The incidence of immediate postoperative complications (restlessness, pallor, nausea/vomiting, respiratory depression) was lowest in the control group.

Postoperative analgesia was least satisfactory with the FD technique, where the first dose of analgesic was required considerably earlier than in the other groups. The mean time until analgesia was required was longest and the total postoperative dose of analgesic smallest, in the group of patients given levorphanol.

Mean arterial $\mathrm{PCO}_{2}$ levels, taken $60-90$ minutes after surgery were lowest with the FD technique and highest when levorphanol had been used. However, in all groups they were within acceptable limits.

\section{Discussion}

Induction hypotension was fairly common with all four techniques and, in view of the later study of Pandit, Dundee, and Stevenson, ${ }^{13}$ using pancuronium as a relaxant, this can probably be attributed to tubocurarine. The administration of thiopentone immediately following the adrenergic blocking drug droperidol is particularly undesirable so far as hypotension is concerned.

Although levorphanol is a long acting narcotic analgesic, it appears to have a slow onset of action. This would account for the more difficult intubating conditions, more frequent response to intubation and greater rise in blood pressure after intubation when it was given.

The greater time taken to prepare a patient for surgery with Innovar, as compared with other techniques, caused difficulties in the clinical situation in which this study 
was carried out, but may not apply elsewhere. A more real problem arose from the 14 patients (28 per cent) who manifested marked respiratory difficulties after the injection of Innovar, as artificial ventilation was almost impossible in the majority of these cases. However, the situation responded rapidly to the administration of a relaxant. This complication, attributable to fentanyl, has been reported by several workers ${ }^{14-16}$ and is, in the opinion of the authors, a major drawback to the use of Innovar for induction of anaesthesia in adults.

The findings of the present study do not substantiate the claims that NLA is accompanied by a greater stability of the cardiovascular system than standard techniques. In fact, both heart rate and blood pressure showed greater variations with neuroleptic techniques than in patients given thiopentone-nitrous oxideoxygen-levorphanol. There seems little to recommend the fentanyl/droperidol technique, as used in this study, for supplementing nitrous oxide-oxygen anaesthesia.

The neurolept techniques were accompanied by the least sweating and patient movement, and this is probably related to the relatively larger doses of narcotic used (Table III). In many cases, this smoothness of anaesthesia did not compensate for the greater cardiovascular instability and, taking all factors into consideration, the authors would not express any preference for any one technique, so far as maintenance of anaesthesia is concerned.

Considering the claims that have been made, the poor postoperative analgesia resulting from any of the techniques other than the control, was disappointing. The brevity of action of fentanyl, which appears to be about half that of comparable doses of morphine, ${ }^{17}$ was undoubtedly responsible for this.

Taking all factors into consideration, our standard technique used for major surgery (thiopentone- tubocurarine-levorphanol-nitrous oxide-oxygen) proved as satisfactory as any of the others used in this investigation (Figure 1). When the length of time taken to induce anaesthesia and the respiratory difficulties experienced with neurolept anaesthesia are taken into consideration, there seems nothing to recommend it in comparison with the standard thiopentone-analgesic sequence.

\section{SUMMARY}

The study was designed to evaluate the usefulness of neurolept-anaesthesia (NLA) for major abdominal and thoracic surgery. A standard technique, in which thiopentone-tubocurarine-nitrous oxide-oxygen was supplemented with intravenous levorphanol, was compared with four other techniques involving the use of various combinations of the drugs commonly used in NLA, i.e. fentanyl and droperidol.

Identical cases, anaesthetised with different techniques, were analysed by sequential analysis.

Induction was slow with neuroleptic drugs and in 28 per cent of cases marked difficulty was experienced in ventilating the patient. Cardiovascular changes at induction were similar with each of the techniques.

There was less sweating and movement of the patients using neuroleptic techniques but heart rate and blood pressure were more stable during maintenance of anaesthesia when levorphanol was used. 
In the postoperative period, the onset of pain was delayed and the need for analgesics less in patients given levorphanol. The authors conclude that neuroleptanaesthesia has no advantages over conventional anaesthesia, so far as major surgery is concerned.

\section{RÉSUMÉ}

La technique anesthésique standard utilisée par les auteurs pour la chirurgie majeure consiste en une induction au thiopentone complétée par du protoxyde d'azote-oxygène et du levorphanol, en administrant de fortes doses de tubocurarine pour assurer le relâchement musculaire. On a comparé cette technique avec une autre où l'on utilise l'Innovar (mélange de fentanyl et de dropéridol) pour l'induction et soit encore l'innovar, soit le fentanyl seul comme complément au protoxyde d'azote. Dans cette étude on n'a pas pu confirmer les prétendus avantages de cette dernière forme de neuroleptanalgésie. Avec le thiopentone comme agent d'induction, le fentanyl s'est montré inférieur au levorphanol comme complément d'anesthésie et même lorsqu'on y ajouté une seule dose de dropéridol, on n'a pas eu de meilleurs résultats qu'avec la technique standard.

\section{REFERENCES}

1. De Castro, G. \& Muxpeleer, P. Anesthésie sans barbituriques: La neuroleptanalgesia. Anesth. et analg. (Paris), 16:1022 (1959).

2. Nilsson, E. Origin and rationale of neuroleptanalgesia. Anesthesiology, $24: 267$ (1963).

3. Bova, G.; Koch, G.; \& vaN DER LINDEN, W. The postoperative course after neuroleptanalgesia. A controlled trial. Acta anaesth. scand., 9:21 (1965).

4. Spoerel, W. E. \& Chan, W. S. Innovar in surgical anaesthesia. Canad. Anaesth. Soc. J., 12: 622 (1965).

5. Brows, A. S. Neuroleptanalgesia. Internat. Anesthesiol. Clin., 7: 159 (1969).

6. Aubry, U.; Carignan, G.; Charette, D.; Keeri-Szanto, M.; \& Lavalee, J. P. Neuroleptanalgesia with fentanyl-droperidol. An appreciation based on more than 1,000 anaesthetics for major surgery. Canad. Anaesth. Soc. J., 13: 263 (1966).

7. Fox, J. W. C.; Fox, E. J.; \& Crandell, D. L. Neuroleptanalgesia for heart and major surgery. Arch. Surv., 94: 102 (1967).

8. Morrison, J. D. Alterations in response to somatic pain associated with anaesthesia xix: Studies with the drugs used in neuroleptanaesthesia. Brit. J. Anaesth., 42: 838 (1970).

9. Morrison, J. D.; Clarke, R. S. J.; \& DUndeE, J. W. Studies of drugs given before anaesthesia. xxı: Droperidol. Brit. J. Anaesth., 42: 730 (1970).

10. Dundee, J. W.; Brown, S. S.; Hamilton, R. C.; \& McDowell, S. A. Analgesic supplementation of light general anaesthesia: a study of its advantages using sequential analysis. Anaesthesia, 24:52 (1969).

11. Armitage, P. Sequential Medical Trials. Oxford: Blackwell (1960).

12. Dundee, J. W.; Hanmlton, R. C.; Clarke, R. S. J.; Armstrong, R.; \& Turkington, E. E. Clinical studies of induction agents. xVII: A comparison of thiopentone and propanidid using multiple preference sequential analysis. Brit. J. Anaesth., 39: 236 (1967).

13. Pandit, S. K.; Dundee, J. W.; \& Stevenson, H. M. S. A clinical comparison of pancuronium with tubocurarine and alcuronium in major cardio-thoracic surgery. Anesth. Analg. Curr. Res. (in press) (1971).

14. Corssen, G., Domino, E. F., \& SweEt, R. B. Neuroleptanalgesia and anesthesia. Anesth. \& Analg., 43: 748 (1964).

15. Ferrari, H. A. \& Stephen, C. R. E. Neuroleptanalgesia: Pharmacology and clinical experiences with droperidol and fentanyl. Sth. med J. (Bgham, Ala.), 59: 815 (1966).

16. Moran, J. H. \& Marshall, B. M. A report on the clinical uses of droperidol and fentanyl. Canad. Anaesth. Soc. J., 13: 272 (1966).

17. Morrison, J. D. Drugs used in neuroleptanalgesia. Internat. Anesthesiol. Clin., 7: 141 (1969). 